\title{
Mixed conducting yttrium-barium-cobalt-oxide for high oxygen permeation
}

\author{
H.W. Brinkman, H. Kruidhof, A.J. Burggraaf \\ Department of Chemical Technology, Laboratory of Inorganic Chemistry, Materials Science and Catalysis, University of Twente, \\ P.O. Box 217, 7500 AE, Enschede, The Netherlands
}

Received 17 January 1994; accepted for publication 14 April 1994

\begin{abstract}
Yttrium-barium-cobalt-oxide (YBC), especially with low $\mathrm{Y}$ content, has been prepared. Oxygen permeation in these materials is very high at moderate temperature. The materials $\mathrm{Y}_{0.05} \mathrm{BaCO}_{0.95} \mathrm{O}_{3-\delta}$ and $\mathrm{Y}_{0.10} \mathrm{Ba}_{0.90} \mathrm{CoO}_{3-\delta}$ consisted of a BaCoO${ }_{3-\delta}$ like main phase and some minor phases. For the $\mathrm{Y}_{0.05} \mathrm{BaCo}_{0.95} \mathrm{O}_{3-\delta}$ material these minor phases were not exceeding 10 vol\%. $\mathrm{Y}_{0.05} \mathrm{BaCo}_{0.95} \mathrm{O}_{3-\delta}$ had the highest oxygen permeation value of $3.9 \times 10^{-7} \mathrm{~mol} / \mathrm{cm}^{2} \mathrm{~s}$ at $900^{\circ} \mathrm{C}$; the surface exchange reaction may be the rate limiting step here. The material $\mathrm{Y}_{0.33} \mathrm{Ba}_{0.67} \mathrm{CoO}_{3-\delta}$ consisted mainly of two unknown cubic phases.
\end{abstract}

\section{Introduction}

In the last few years mixed (oxygen ionic and electronic) conducting materials have attracted much attention. These materials can be used as oxygen separation membranes, as cathodes in solid oxide fuel cells and in electroanalytic reactors.

A material of particular interest in our group is the nonstoichiometric perovskite-type material lanthanum-strontium-cobalt-oxide $\left(\mathrm{La}_{x} \mathrm{Sr}_{1-x} \mathrm{CoO}_{3-\delta}\right.$, abbreviated as LSC) [1]. A possible new mixed conducting material that is familiar to LSC is yttriumbarium-cobalt-oxide $\left(\mathrm{Y}_{y} \mathrm{Ba}_{x} \mathrm{Co}_{z} \mathrm{O}_{3-\delta}\right.$, abbreviated as YBC). When the $\mathrm{La}^{3+}$-ion, which normally occupies the $A$ position in the perovskite lattice, is replaced by a smaller $\mathrm{Y}^{3+}$-ion and the $\mathrm{Sr}^{2+}$-ion is replaced by a larger $\mathrm{Ba}^{2+}$-ion, the difference in cation radii (between the $\mathrm{La}^{3+}$ and $\mathrm{Sr}^{2+}$-ions on one hand and the $\mathrm{Y}^{3+}$ and $\mathrm{Ba}^{2+}$-ions on the other hand) is increased in the YBC-case and the yttrium-barium-cobalt cation lattice will decrease. This promotes cation ordered structures in which vacancies are transformed to regular sites. In some cases preferential pathways are formed [2]. It is anticipated that introduction of defects into this type of (locally) ordered structures results in increased oxygen permeation.

In this letter a description is given of a preliminary investigation performed on $\mathrm{Y}_{y} \mathrm{Ba}_{x} \mathrm{Co}_{z} \mathrm{O}_{3-\delta}$, especially in the low $\mathrm{Y}$ regime $(y=0.05-0.33)$. After preparation of several samples with different nominal compositions, the phase compositions have been analyzed and some initial oxygen permeation experiments have been performed. An extended paper about this very promising new type of material will be produced later [3].

\section{Preparation of the materials}

The material $\mathrm{Y}_{0.33} \mathrm{Ba}_{0.67} \mathrm{CoO}_{3-\delta}$, abbreviated as $33 \mathrm{YBC}$, has been prepared according to the citrate synthesis [4]. The necessary amount of $\mathrm{Y}_{2} \mathrm{O}_{3}$ was dissolved under heating in nitric acid $(65 \%$ solution). After cooling down and diluting, $\mathrm{Ba}\left(\mathrm{NO}_{3}\right)_{2}$ 
was added. After diluting again until the solution became clear, the $\mathrm{Co}\left(\mathrm{NO}_{3}\right) \cdot 6 \mathrm{H}_{2} \mathrm{O}$ and citric acid were added. After stirring some time, ammonia ( $25 \%$ solution) was added in small amounts until the $\mathrm{pH}$ of the solution was about 3.5. The solution was heated after which its volume decreased and a viscous paste formed; this paste swelled during heating until spontaneous ignition and pyrolysis took place. The so formed $33 \mathrm{YBC}$ powder was calcined for $12 \mathrm{~h}$ at $950^{\circ} \mathrm{C}$ in air, after which it was wet milled with acetone. From the powder a pellet was pressed and sintered for $5 \mathrm{~h}$ at $1200^{\circ} \mathrm{C}$ in air. The density of the pellet measured by Archimedes method (using mercury) was $5.54 \mathrm{~g} / \mathrm{cm}^{3}$.

The materials $\mathrm{Y}_{0.05} \mathrm{BaCo}_{0.95} \mathrm{O}_{3-\delta}(5 \mathrm{YBC} 95)$ and $\mathrm{Y}_{0.10} \mathrm{Ba}_{0.90} \mathrm{CoO}_{3-\delta}(10 \mathrm{YBC})$ were prepared by means of the EDTA synthesis, related to the citrate synthesis. The only differences were that here EDTA is used instead of citrate acid, that the $\mathrm{pH}$ had to be around 5-6 after adding ammonia and that a sand bath was used to heat the solution until compleximerization. After heating, a "sticky" paste resulted, which was calcined for $4 \mathrm{~h}$ at $800^{\circ} \mathrm{C}$ in air and dry-milled afterwards at room temperature. From these powders pellets were pressed and sintered for $10 \mathrm{~h}$ at $1100^{\circ} \mathrm{C}$ in air. The densities of the pellets were $4.83 \mathrm{~g} / \mathrm{cm}^{3}$ and $4.82 \mathrm{~g} / \mathrm{cm}^{3}$ for $5 Y B C 95$ and $10 Y B C$, respectively.

A detailed description of the syntheses and characterizations will be given elsewhere [3].

\section{X-ray diffraction and TEM analysis}

By means of X-ray diffraction (Philips PW1370 diffractometer with $\mathrm{Cu} \mathrm{Ka}$-radiation) and TEM (Philips CM30 operating at $300 \mathrm{kV}$ ) phase analyses were performed. Pellets which had been sintered in air were crushed to powder, and that powder was analyzed. All materials were to some extend multiphasic. In Fig. 1 the XRD pattern of 5 YBC95 is shown.

Both the 5YBC95 and the 10YBC materials consisted mainly of a $\mathrm{BaCoO}_{3-\delta}$ type phase, which has a hexagonal crystallographic unit cell with space group $\mathrm{P}_{3} / \mathrm{mmc}$ [5]. Minor phases were $\mathrm{Y}_{2} \mathrm{O}_{3}, \mathrm{Co}_{3} \mathrm{O}_{4}$ and $\mathrm{BaCO}_{3}$ (barium carbonate), which all could be detected in the XRD pattern (see e.g. Fig. 1). For $5 \mathrm{YBC} 95$ the total amount of minor phase was less

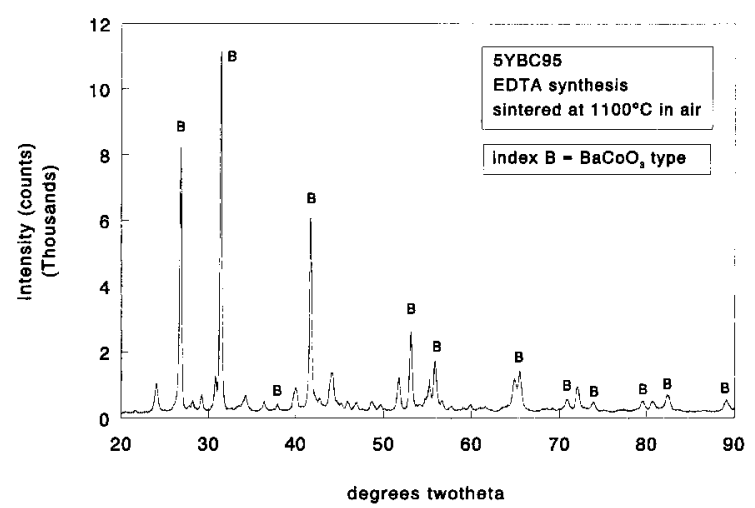

Fig. 1. X-ray diffraction pattern of $5 Y B C 95$, after sintering at $1100^{\circ} \mathrm{C}$ in air. The $\mathrm{BaCoO}_{3}$ type peaks are marked.

than $10 \%$, estimated from the XRD pattern. For $10 \mathrm{YBC}$ the second phase content was somewhat higher. By means of TEM and the selected area electron diffraction facility connected to it, the $5 \mathrm{YBC} 95$ material was analyzed. The $\mathrm{BaCoO}_{3-\delta}$ type phase consisted besides $\mathrm{Ba}$ and $\mathrm{Ca}$ also of $\mathrm{Y}$, which indicates that a $\mathrm{Y}-\mathrm{BaCoO}_{3-\delta}$ solid solution has been formed.

The 33YBC material consisted of at least three phases, which could not all be analyzed. One main fraction had a structure related to the structure of cubic $\mathrm{Ba}\left(\mathrm{Na}_{0.25} \mathrm{Ta}_{0.75}\right) \mathrm{O}_{3}$ (JCPDS card 18-1200). Another main fraction had most probably a structure related to cubic $(\mathrm{Ca}, \mathrm{Ce}, \mathrm{La}, \mathrm{Nd}, \mathrm{Pr})(\mathrm{Ti}, \mathrm{Al}, \mathrm{Fe}) \mathrm{O}_{3}$ (JCPDS card 15-158). A minor third fraction showed the most resemblance with the $\mathrm{Y}_{2} \mathrm{O}_{3}$ phase.

\section{Oxygen permeation measurements}

For oxygen permeation measurements the pellets were shaped into disks of $12 \mathrm{~mm}$ diameter and $2 \mathrm{~mm}$ thickness. A disk was mounted to an oxygen permeation quartz reactor tube using a glass seal. The experimental equipment has been described in detail in [6].

Along one side of the disk air was flown $\left(P_{\mathrm{O}_{2}}=0.21\right.$ atm, the feed side) while the other (permeate) side was exposed to a helium flow. The sweep rate of the helium flow determined the oxygen partial pressure; in our experiments a nominal oxygen partial pressure of around $10^{-4} \mathrm{~atm}$ at the permeate side has been applied. The amount of oxygen that permeated from 
the high oxygen partial pressure side through the disk to the helium flow was measured by a gas chromatograph. The advantage of this measurement was that possible leakage through pores or cracks in the disk or in the seal could be detected by measuring the amount of nitrogen (from the air) in the helium flow; nitrogen can only pass by pores in the ceramic disk (or the seal) and does not permeate through fully dense material. Correction could then be made for this leakage.

After sealing the pellets to the quartz reactor, tests were performed to investigate whether the pellets were gas tight. The 33YBC pellet was fully gas tight, but both the 5YBC95 and 10YBC pellets showed some leakage. During the measurements, the amount of oxygen that leaked through pores, cracks or seal (correlated to the amount of nitrogen ) was not larger than about $10 \%$ of the total oxygen flux. Oxygen permeation through the $33 \mathrm{YBC}$ material was measured between 600 and $900^{\circ} \mathrm{C}$ while permeation through the $5 \mathrm{YBC} 95$ and $10 \mathrm{YBC}$ materials was measured between 900 and $1100^{\circ} \mathrm{C}$. Correction for leakage was applied. The oxygen permeation fluxes are shown in Fig. 2 in an Arrhenius plot. In Table 1 the oxygen permeation at $900^{\circ} \mathrm{C}$ is given together with the apparent activation energy for oxygen permeation. The fluxes through the 5YBC95 and 10YBC samples can be considered to be high; the lower the Y content, the higher the oxygen permeation.

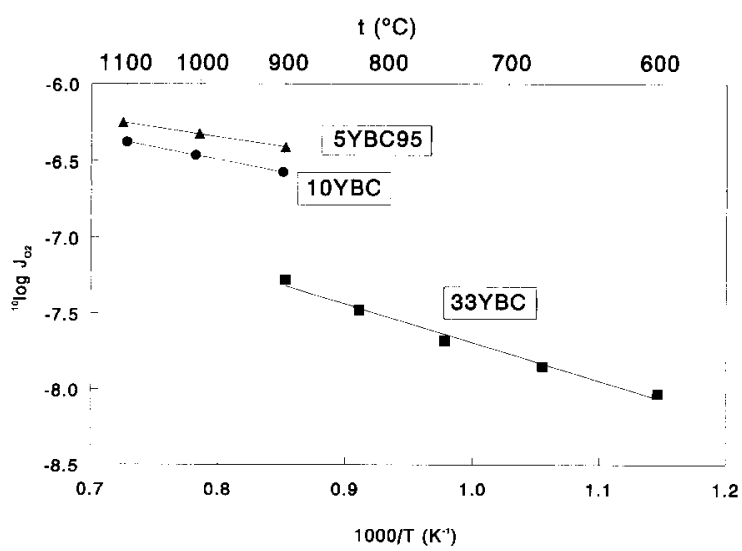

Fig. 2. Oxygen permeation fluxes $\left(J_{\mathrm{O}_{2}}\right.$ in $\left.\mathrm{mol} / \mathrm{cm}^{2} \mathrm{~s}\right)$ of $5 \mathrm{YBC} 95$, $10 \mathrm{YBC}$ and $33 \mathrm{YBC}$ as a function of temperature.
Table 1

Oxygen permeation results. Pellet thickness $=2 \mathrm{~mm} ; P_{\mathrm{O}_{2}}^{\text {high }}=0.21$ atm; $P_{\mathrm{O}_{2}}^{\text {low }}=10^{-4}$ atm (nominal)

\begin{tabular}{llll}
\hline Material & $\begin{array}{l}J_{\mathrm{O}_{2}} \text { at } 900^{\circ} \mathrm{C} \\
\left(\mathrm{mol} / \mathrm{cm}^{2} \mathrm{~s}\right)\end{array}$ & $\begin{array}{l}E_{\mathrm{a}} \\
(\mathrm{kJ} / \mathrm{mol})\end{array}$ & $\begin{array}{l}\text { Range for } E_{\mathrm{a}} \\
\left({ }^{\circ} \mathrm{C}\right)\end{array}$ \\
\hline $5 \mathrm{YBC} 95$ & $3.9 \times 10^{-7}$ & 24 & $900-1100$ \\
$10 \mathrm{YBC}$ & $2.7 \times 10^{-7}$ & 31 & $900-1100$ \\
$33 \mathrm{YBC}$ & $0.5 \times 10^{-7}$ & 49 & $600-900$ \\
\hline
\end{tabular}

\section{Discussion and conclusions}

YBC samples prepared by means of the citrate or EDTA synthesis are not single phase, although especially 5 YBC95 contains only a small amount of second phases. Especially the occurrence of $\mathrm{BaCO}_{3}$ (barium carbonate) in the material is however not desired because it might influence the surface exchange properties. It is very hard to remove this phase from the material.

During measuring the oxygen permeation, the effective oxygen partial pressure at the helium (permeate) side became higher as the temperature increased; higher temperatures gave higher oxygen permeation fluxes which resulted by means of concentration polarization at the permeate side in an effective higher oxygen partial pressure. The permeation fluxes given in this letter were not corrected for this change of oxygen partial pressure with temperature. This implies, however, that the real, corrected permeation values are higher at higher temperatures than the values reported here.

Although the 33YBC material was gas tight during sealing on the quartz reactor tube, during measuring at about $750^{\circ} \mathrm{C}$ the pellet was leaking $\left(\mathrm{N}_{2}\right.$ was detected by the gas chromatograph); above and under this temperature the pellet became gas tight again. This leakage could be caused by a phase transition occurring in the $33 \mathrm{YBC}$ material at about $750^{\circ} \mathrm{C}$. The same phenomena have been observed with the $5 \mathrm{YBC} 95$ and $10 \mathrm{YBC}$ materials below $900^{\circ} \mathrm{C}$. After measuring for a long time with the 33YBC pellet, the material broke into pieces.

With the 5YBC95 and 10YBC materials some oxygen permeation measurements have been performed with pellets of $1 \mathrm{~mm}$ thickness. The oxygen permeation fluxes were (within the measuring error) equal to the fluxes through the $2 \mathrm{~mm}$ pellets. This re- 
sult suggests that the surface exchange reaction (oxygen diffusing in or out of the material) is rate limiting for the oxygen permeation process, or that the increased flux through the thinner sample causes an increase in the oxygen partial pressure at the permeate side (and so a decrease of the driving force), which just compensates for the decrease of the bulk resistance against permeation. This is under investigation now.

As a conclusion it can be said that the system yttrium-barium-cobalt-oxide is a very promising material for oxygen permeation, with very high fluxes.

\section{Acknowledgement}

Miss B. Abadie, Mr. J. Boeijsma, Dr. Ir. T. Kach- licki and Drs. R.H.E. van Doorn are very much acknowledged for preparing the materials, helping with XRD analysis, performing the TEM measurements and assisting in permeation measurements, respectively. Dr. H.J.M. Bouwmeester is very much acknowledged for useful discussions.

\section{References}

[1] H. Kruidhof, H.J.M. Bouwmeester, R.H.E. van Doorn and A.J. Burggraaf, Solid State Ionics 63-65 (1993) 816.

[2] M.P. van Dijk, A.J. Burggraaf, A.N. Cormack and C.R.A. Catlow, Solid State Ionics 17 (1985) 159.

[3] H.W. Brinkman, H. Kruidhof, H.J.M. Bouwmeester and A.J. Burggraaf, to be published.

[4] D.H.A. Blank, H. Kruidhof and J. Flokstra, J. Phys. D 21 (1988) 226.

[5] H. Taguchi, Y. Takeda, F. Kanamaru, M. Shimada and M. Koizumi, Acta Cryst. B33 (1977) 1299.

[6] H.J.M. Bouwmeester, H. Kruidhof, A.J. Burggraaf and P.J. Gellings, Solid State Ionics 53-56 (1992) 460. 